\title{
Semiotics Study on Poster Film The Pursuit of Happyness
}

\author{
Septi Rizki Nuryani \\ Gunadarma University, Salemba Raya No. 53 Jakarta Pusat 10440, Indonesia
}

\begin{abstract}
This study concerns on Semiotics fields. The problems of the study are what signs that represent film The Pursuit of Happyness on poster; what meanings are contained in the poster of the film; and how is poster design of The Pursuit of Happyness attracting the audience's attention. The research aims to find out signs that represent the film; to find out meanings that contain on poster; and to find out how the design used to attract attention of the audience. This study uses qualitative method. The findings of the study shows that there are 9 signs on the poster namely white background, the shining light between two main characters, the use of colour and size on two words ('pursuit' and 'happy'), the position of some words, the symbol of father and son, gesture of the two main characters, the appearance of two main character, facial expression and the intention of the slogan 'inspired by true story' as well as Christmas 2006. Each sign has meaning. The way illustrator attracting audience's attention is very smooth. Although the poster looks simple, the visual and the way s/he uses the colours. By the name of actor, the slogan, and the design, the illustrator is successful in building people's enthusiasms on the film.
\end{abstract}

Keywords: film, poster, semiotics

DOI: $10.7176 /$ JLLL/54-06

Publication date:March $31^{\text {st }} 2019$

\section{Introduction}

The role of media is inseparable from human growth and development in this modern era. It is undeniable that human has always followed the media. Media has become a tool in spreading information, acknowledge, even ideology to the world. Eriyato (Halim, 2017: 56) explains that media unintentionally becomes a tool in expanding values or dominant discourses that are considered right until it comes to people's minds and makes it to be truth. Film is one of communication media with a broad mass; and film holds a key on space and time. The deployment of film will be faster enlarged by media mass. Film is an audiovisual communication media conveying a message to a group of people in a particular place. The messages on the film take any form depending on the content of it. Film is also considered as a powerful medium in communication for target period because it provides vivid visual and audio. By visual and audio, film can bring many ideas behind the film. Film can display a real life and even affect the audience. Initially film only shows colourless visual--black and white-even it has not audio. However, film is different from earlier in era of technological advancements nowadays. It has an audiovisual even has an effect on visual. Amheim (1957: 34) states that film is nothing but the feeble mechanical reproduction of real life. The concepts of Amheim refers that films are based on original stories, but not a few films are based on fiction. Although the films are based on fiction, truly the authors have inserted a storyline which they have felt in real life. They use their experience as a reference in producing films. In other words, film is representation of a real life.

Things have never overlooked when a film industry creates a film is forming posters. Poster is a large notice, often with picture on it, put in a public place to advertise something; is a large picture that is printed on paper and put on a wall as decoration (Oxford, 2010: 1142). Poster is a placard placed in a public place) in form of announcements or advertisements) (KBBI, 2008: 1096). Posters are mass-produced advertisements or announcements. It can be found on road, malls or cinemas. Generally posters are made in large size on paper to show the audience. It contains illustrated images with various elements. According to Sudjana (Riyana, 2012: 118) poster is a media combines visual designs with colours and messages intentionally to attract audience's attention but it needs time to understanding the meaning ideas in memories. Commercially poster is useful to advertise a product, an activity, an entertainment event, or certain events. It becomes one of the promotional media that is widely used by industries especially film industries. However, there are also posters made limited for artistic.

Poster is a significant part that has included after film. All films in the world must have poster as a promotional media. Even if it is a theatre musical, theatre drama, or short film, it must have posters. Film industries are highly utilizing posters to popularize their various films. The poster will often be seen by cinema visitors because one of its usages is for promotion. If the poster displays on the roadside, it will be in front of mall building or on front wall of the cinema. The poster film design is a key to influence the audience to watch it.

Human communicates by using signs: such as pictures, words, number. Sign is one of communication arts that often used in conveying messages by individuals or groups. Film industries are one example relaying information through symbols on posters. The study of signs and everything relates to sign is 'symptom' (Oswald, 
2012: 8). Oswald (2012: 8) uses 'semiotic' to refer to the ensemble of signifying operations at work sign systems, such as a brand, an advertising text, or a retail setting. According to Saussure (Guiraud, 1975: 1-2) Semiotics is;

Language is a system of sign that express ideas, and is therefore comparable to writing, to the deaf mute alphabet, to symbolic rites, to codes of good manners, to military signal, etc. It is simply the most important of these systems. A science that studies the life of signs in society is therefore conceivable: it would be a part general psychology: we shall call it semiology (from the Greek semeion, sign). Semiology would teach us what sign are made of and what laws govern their behaviour.

Semiotics is a study of (a) signs, which means it studies various differences in signs, meanings, and relationships with people who uses signs; (b) codes that form signs or systems, it means that various codes are formed with the aim of the needs of society, culture, or the media delivering information; (c) culture that uses signs or systems. Culture is a place of sign and system meets.

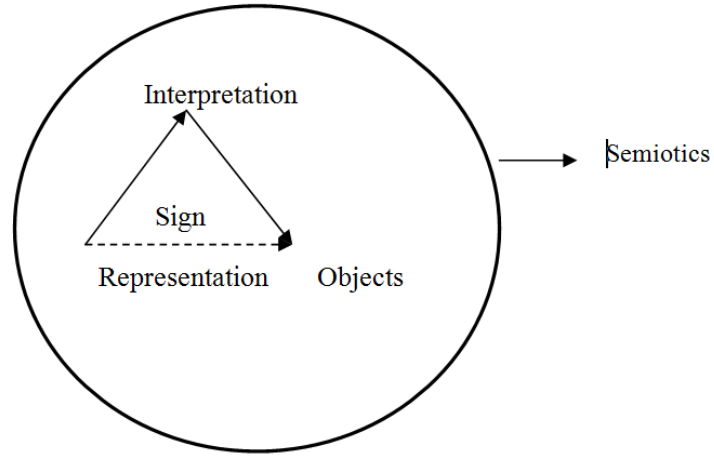

Pierce Semiotic's Model

Pierce puts forward the theory of triangle meaning consisting of three main elements namely representation (sign), object, and interpretation. According to Pierce a sign or representation is something that represents other than the sign itself. The other is called interpretation of the first sign and it will refer to a particular object. Signs according to Pierce consist of symbols (signs emerge from agreement), icons (signs appear from physical representation) and index (signs that arise from the causal relationship) and this is called object. Avotins (2019) explains the meaning of colour into:

- $\quad$ red: passion, drama, danger, courage, strength, power

- orange: encouragement, excitement, enthusiasm, happiness, joy

- yellow: optimism, youthful, fresh, energy, but sometimes signifies cowardice

- $\quad$ pink: sensitivity, love, femininity, safety, vulnerability

- $\quad$ blue: trust, shade of sea \& sky, tranquillity, serenity, peace, loyalty, integrity, responsibility

- green: growth, health, nature, renewal, life, refreshing, peaceful, but it can be materialistic, possessive

- violet: spirituality, reflection, self awareness, royalty, luxury, if it overuses, it can be irritability and arrogance

- brown: earth, stability, solid, natural, simple, it is also thought to be dull, but is reliable and wholesome (although frugal and stingy, it is a colour safety, confidence, honesty, sincerity)

- grey: compromise, unemotional (it cannot be considered as a glamorous colour, yet it is still elegant)

- black: mystery, strong, powerful, sophisticated, sexy, secretive, pessimism, lack of hope

Many researchers have done a similar research in Semiotics fields. Da Silva (2017) and Natashia (2015) have analyzed an advertisement by applying Semiotics as a tool. Da Silva on her research concerns to the four main aspects of Semiotics in her research while Natashia concerns to the concept of beauty on her research. The current research is limited to the meaning of signs on poster. In accordance with meaning of signs, the problems of the study are what signs that represent film The Pursuit of Happyness on poster; what meanings are contained on poster of the film; and how is poster design of The Pursuit of Happyness attracting the audience's attention. The research aims to find out signs that represent the film; to find out meanings that contain on poster; and to find out how the design used to attract attention of the audience.

\section{Methods}

This study uses qualitative method in analyzing poster of The Pursuit of Happyness. As stated in Kirk and Miller (1986: 9) qualitative research is a particular tradition in social science that fundamentally depends on watching on people in their own territory and interacting with them in their own language, on their own terms. The approach used in this study is semiotics which emphasizes the attention to the signs system about how meaning is constructed through the poster. This study uses poster film of The Pursuit of Happyness as the primary data. The data of this study is selected based on purposive sampling. Riazi (2016: 194) purposes that purposive sampling is also used in the qualitative phase of the MMR (Mixed-Method Research) study in which specific 
criteria will be used to determine the sample used for collecting more in-depth data. The reason for choosing the data based on its popularity and its design. The data will be explained descriptively in discussion.

\section{Result and Discussion}

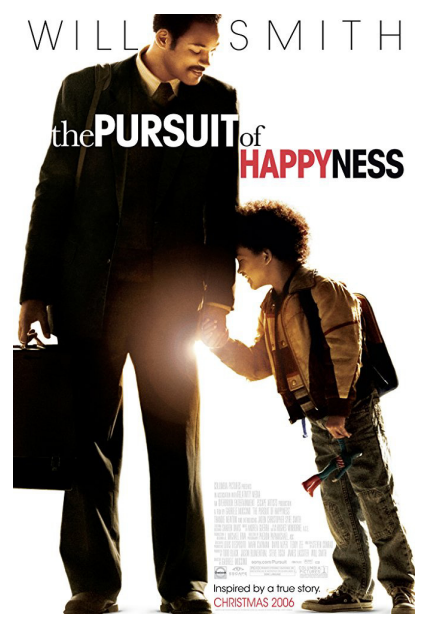

The Pursuit of Happyness is a biography film directed by Gabriele Muccino as well as reproduced by Will Smith, Steve Tisch, James Lassiter, Todd Black and Jason Blumenthal. This film shows a struggle life of Chris Gardner before becoming an entrepreneur, investor, stock broker, in the early 1980s. It is published on 15 December, 2006 in United States. It becomes popular and trending film at the time.

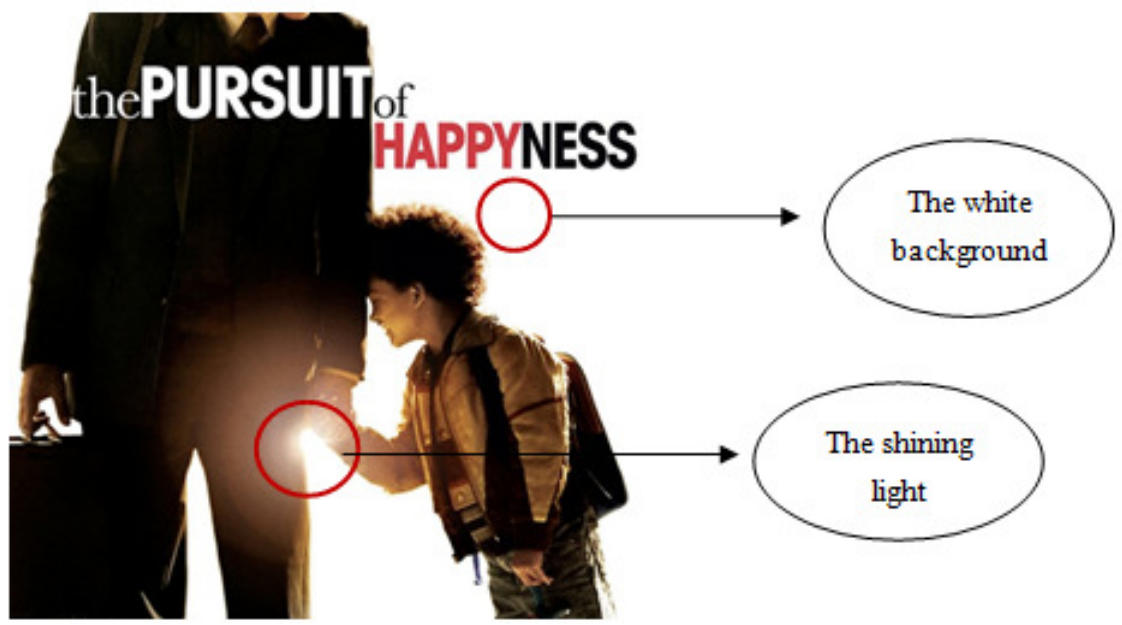

Initially the background of the film is completely white to make it stands out and become an eye catching of the audiences to the two main characters on poster. Kouwer (1949: 101) explains white colour means freedom. It tends towards the future, towards everything that will or may come; white is the absolute beginning. The colour white is usually attributed to the prime era. The colour of the background means purity, new beginning of a new life. Moreover there is light shining between the characters indicates sunset that began to arise. The shining light means the beginning of a new life for bright future. 


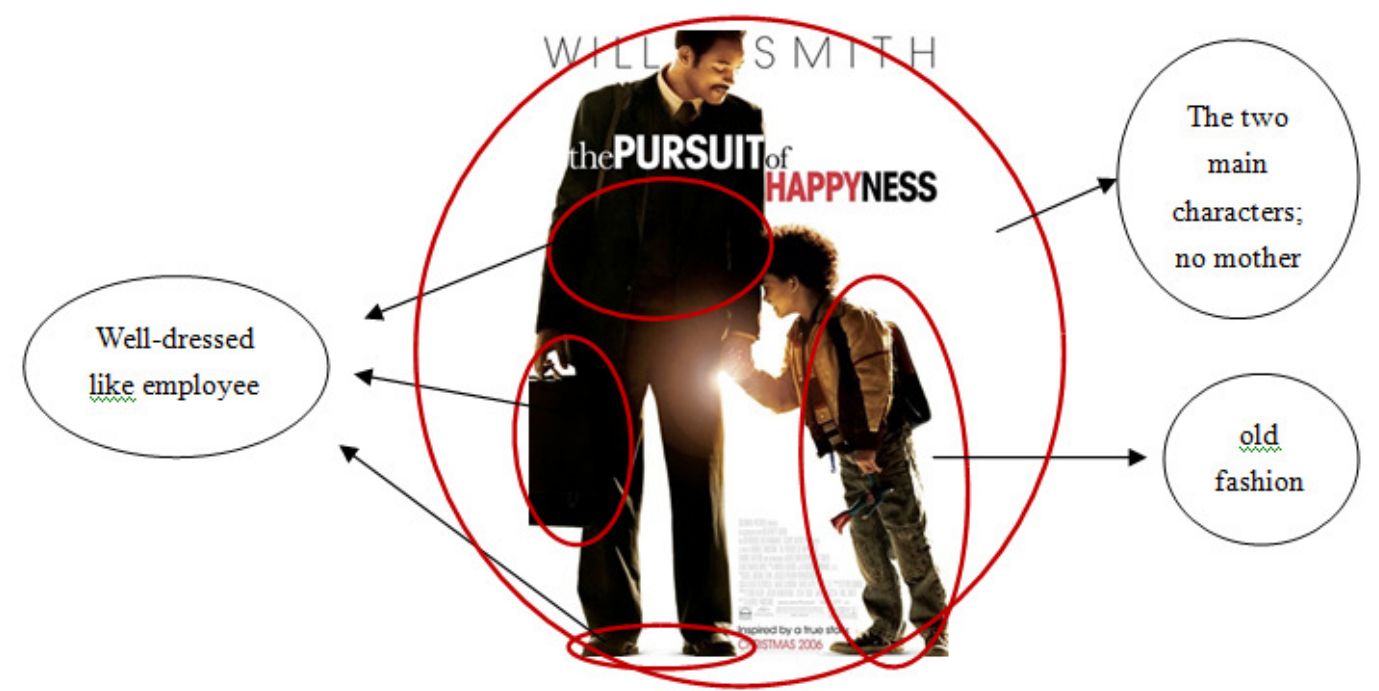

There are two characters seen on poster which shows the central focus on the film is father and son. There is no mother figure which means the film concerns a broken family. By not applying mother figure on poster, it illustrates that the mother might be died, left, or divorced. Life background of the characters can be seen by their clothes. The father wears a well dressed completely with brief case and shoes. The son wears old clothes that have not luxury impression on it. Their appearance illustrates that their life is not prosperous. In other words, the father wears a suit like employee which means he has to work to support his beloved son.

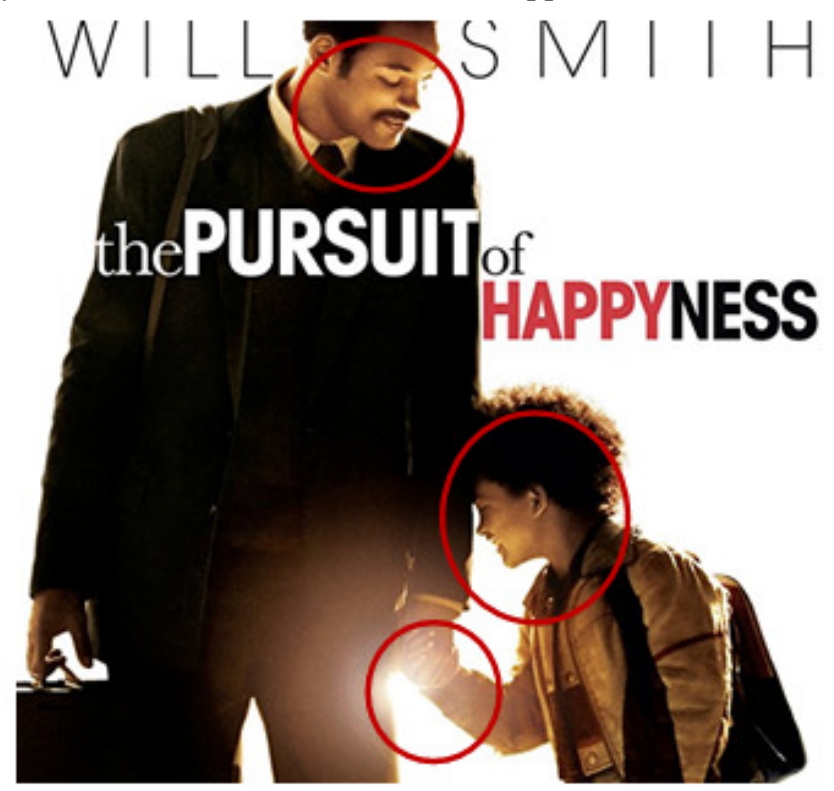

Next they are holding hands while the son leans towards his father hands. These indicate a trust bounding between father and son. The son depends himself completely to his father and his father supports him. Smile expressions from two of them have a different meaning. Chris's son smiles with laugh happily demonstrates he feels happy beside his father; while Chris smiles staring at his son indicates he truly loves his son. His stare looks like father who is waiting for his son's future. By looking down at his son and the two of them holding hands, it shows a strong love between father and son. 


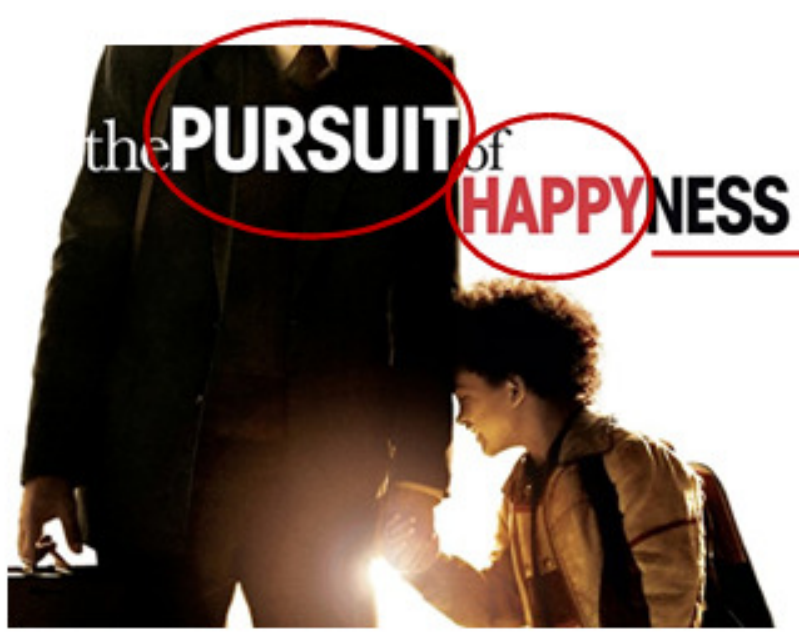

Red and white colours are used in naming the title. Red colour is identical with blood. Someone who is injured will feel pain and suffer. Blood will appear from the scar. Thus what does the relation between blood and the red colour 'happy'? It is the feeling of pain (from the red colour) that relates to the word 'happy' because the way towards 'happy' is full of pain and struggle; however, the blood does not appear in film. The relation of blood and the colour red 'happy' is limited to the state that illustrated from both of them. 'ness' at the back of happy is coloured black which demonstrates mysterious. It can be that the illustrator wants to make 'happy' still mysterious; or just using black in order to make it seen (because of the white background, the illustrator applies black as a neutral colour in opposing white). Then the word 'pursuit' has written in white colour makes it seen against the background of black. 'Pursuit' and 'happy' is the main element in this movie and is typed in a big size word. The word 'pursuit' means the act of trying, looking to find something and 'happy' means feeling of pleasure (pleased). Both of words represent that the film regards trying to find the state of pleasure. Besides, the positioning of 'pursuit' is in Chris's chest in which making it points out hope; and 'happy' in his son's head means son's happiness. This illustrates that the father hope in trying to search happiness for his son.

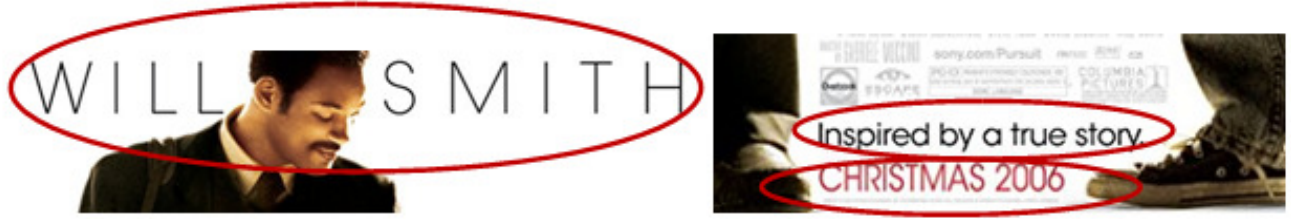

The name Will Smith is used on top of the poster. Will smith is a very well-known American actor. The film industry intentionally uses the name as a commercial promotion to make people willing to watch it. The next following the slogan 'inspired by a true story' written in the bottom of the poster intentionally draws the audience's attention and makes the film seem based on someone's experience. The words 'Christmas 2006' below the poster is also intentionally attract audience's attention. The themes of happiness, unity, family love are identical with Christmas day. It reassures people to go and watch the film with their families.

Therefore from the analysis above, it can be drawn that there are many signs encounters on the poster. Those are white background, the shining light between two main characters, the size of the two words ('pursuit' and 'happy') on poster, the use of the colour on some words, the position of some words, the symbol of father and son, gesture of the two main characters, the appearance of two main character, facial expression and the intention of slogan 'inspired by true story'.

\section{Conclusion}

Film is one of communication media with a broad mass; and film holds a key on space and time. Film can display a real life and can even affect the audience. Things have never overlooked after film are poster. Poster is significant part which has to include after film has created. All films in the world must have poster as its promotional media. Even if it is a theatre musical, theatre drama, or short film, it must have posters. The industries are highly utilizing popularize their films. The poster will often be seen on the road, on the building mall, even on the front wall of the cinema. The poster film design is a key to influence audience to watch it. By applying Semiotics in the research, it aims to find out what signs which represent the film The Pursuit of Happyness on poster; to find out meanings that contain on poster; and to find out the way design used to attract attention of the audience.

The findings of the study shows that there are 9 signs on the poster namely white background, the shining light between two main characters, the use of the colour and size on two words ('pursuit' and 'happy'), the 
position of some words, the symbol of father and son, gesture of the two main characters, the appearance of two main character, facial expression and the intention of the slogan 'inspired by true story' as well as Christmas 2006. Each sign has meaning. For instance white background means the beginning of a new life for the two main characters. The shining light implicitly demonstrates a hope for a bright future of two main characters. The big size of words 'pursuit' and 'happy' means that film concerns two main ideas--it is the struggle in searching for happiness. The red and white colour of the words 'pursuit' and 'happy' is to highlight the words. The white colour of 'pursuit' in father's chest means hope and red colour of 'happy' expresses pain and sorrow. Illustrator indicates that to reach happiness is full of the struggle through pain and sorrow. The symbol of two main characters describe that the film tells a story between father and son. The gestures of holding hand while the son leans towards his father and his father supports him. The facial expression shows a different meaning. The son smiles with laugh happily expresses that he feels happy beside his father. The father smiles staring at his son indicates he loves his son, loves to see his happiness and looks forward to his son's future. By father who looking down staring at his son and both of them holding hands, it represents a strong love between father and son. The slogan 'inspired by a true story' written in the bottom corner of the poster intentionally draws the audience's attention and makes it seem more realistic. The words 'Christmas 2006' below the poster is also intentionally attract audience's attention. Christmas is identical with happiness, unity, family love and the film suitable with this theme. By publishing the film during the Christmas holiday, it reassures people to go and watch the film with family. The way illustrator attracting audience's attention is very smooth. Although the poster looks simple, the illustrator has inserted many meanings behind symbol. It can be seen by the way s/he creates the text, the visual and the way s/he uses the colours. By the name of actor, the slogan, and the design, the illustrator is success building people's impression to make them enthusiasms on film.

\section{References}

Arnheim, R. (1957). Film as Art. London: University of California Press.

Avotins, G. (2019). Color Meaning and Psychology. [Online] Available: http://graflx.com/color-psychologyemotion-meaning-poster/

Da Silva, A. M. (2017). A Semiotic Study of One Ready-To-Drink Tea Billboard Advertisement in Jakarta. Lingua Cultura, 11(2), 73-77.

Guiraud, P. (1975). Semiology. London: Routledge \& Kegen Paul.

Halim, S. (2017). Semiotika Dokumenter: Membongkar Dekonstruksi Mitos Dalam Media Dokumenter. Yogyakarta: Deepublish.

Hornby, A. (2010). Oxford Advanced Leaner's Dictionary, $8^{\text {th }}$ edition. Oxford: Oxford University Press.

Kirk, J. \& Miller, M. L. (1986). Reliability and Validity in Qualitative Research. London: Sage Publications.

Kouwer, B. J. (1949). Colors and Their Character: A Psychological Study. Netherlands: Springer-Sciencet Business Media, B. V.

Natashia, D. (2015). Konsep Cantik Pada Iklan Cetak Majalah Kartini Tahun 2014 \& Koran Kompas Tahun 1979: Analisis Semiotik. Lingua Cultura, 9(2), 88-93. 